\title{
ODONTOHEBIATRIA: UMA NOVA ESPECIALIDADE NA ODONTOLOGIA
}

\author{
ODONTOHEBIATRY: A NEW SPECIALITY IN ODONTOLOGY
}

\author{
Regina Aparecida Segatto Saiani ** \\ Alexandra Mussolino de Queiroz* \\ Maria Stella Gaspar Gomes Raffaini ** \\ Cristhiane Ristum Bagatin-Rossi **
}

\section{RESUMO}

A adolescência é uma fase de crescimento rápido e de transformações físicas, sociais e psicológicas pelas quais o indivíduo passa da infância ao estado adulto. Essa fase apresenta um significado bastante importante na vida de cada indivíduo, requerendo atenção e linguagem especial. $\mathrm{O}$ interesse no estudo e no entendimento da adolescência remete ao final do século passado, quando já havia médicos interessados no crescimento e desenvolvimento dos adolescentes e em suas doenças. $\mathrm{Na}$ Odontologia, essa especialidade é denominada odontohebiatria. Assim, o propósito deste trabalho é descrever, por meio de revisão da literatura, as alteraçôes que podem ocorrer na adolescência com implicaçôes diretas na saúde bucal.

DESCRITORES: Odontologia do adolescente - Hebiatria

\section{ABSTRACT}

The adolescence is a phase of fast growth and physical, social and psychological transformations when the individual passes of infancy to the adult state. This phase shows an important meaning in the life of each individual requiring attention and special language. The interest in the study and agreement of adolescence sends to the end of the last century, when there were doctors interested in the growth and development of the adolescents and their illnesses. In dentistry this speciality is called odontohebiatry. Thus, the aim of this work is to describe, by means of revision of literature, the alterations that can occur in the adolescence with direct implications in oral health.

DESCRIPTORS: Adolescent dentistry - Hebiatry

* Professora Assistente da Disciplina de Odontopediatria do Departamento de Clínica Infantil, Odontologia Preventiva e Social da Faculdade de Odontologia de Ribeirão Preto da Universidade de São Paulo - FORP/USP.

** Pós-graduanda do curso de mestrado em Odontopediatria Departamento de Clínica Infantil, Odontologia Preventiva e Social da Faculdade de Odontologia de Ribeirão Preto da Universidade de São Paulo - FORP/USP. 
Saiani RAS, Queiroz AM, Raffaini MSGG, Bagatin-Rossi CR. Odontohebiatria: uma nova especialidade na odontologia. Revista de Odontologia da Universidade Cidade de São Paulo 2008 jan-abr; 20(1):60-5

\section{INTRODUÇÃO}

A adolescência, do latim "adolesco" que significa crescer, desenvolver-se (Teixeira $\left.{ }^{19}, 2005\right)$, é uma fase específica do desenvolvimento humano, caracterizada por um período de mudanças e transformaçóes múltiplas, profundas e fundamentais para que o ser humano possa atingir a maturidade e inserir-se na sociedade no papel de adulto (Albuquerque E Simōes ${ }^{1}$, 2003). Em outras palavras, é a passagem gradual entre a infância e o estado adulto e se caracteriza por profundas transformaçóes psicológicas, somáticas e sociais (Teixeira $\left.{ }^{19}, 2005\right)$.

Segundo a Organização Mundial de Saúde $\left(\mathrm{OMS}^{23}\right)$, a adolescência pode ser inserida na faixa etária entre os 10 e 20 anos, ou seja, a segunda década de vida.

Essa fase tem grande significado na vida de cada indivíduo requerendo, assim, atenção e linguagem especial (Bussadori e Masuda ${ }^{2}$, 2005). É uma época de conflitos que pode levar a comportamentos variados (Teixeira ${ }^{19}$, 2005) quando as maiores preocupaçóes estáo relacionadas ao temperamento imprevisível, ao uso de drogas, à depressão, ao sexo, aos namoros, à propensão ao suicídio e aos distúrbios alimentares (Bussadori e Masuda ${ }^{2}$, 2005). Diante disso, existe a necessidade de atuação de diversos profissionais para um completo entendimento da saúde do adolescente, e para lhe dar um suporte, a fim de que possa conviver em interdependência sadia com a sociedade (Teixeira $\left.{ }^{19}, 2005\right)$.

$\mathrm{O}$ interesse para o estudo e o entendimento da fase da adolescência remete ao final do século passado, quando já havia médicos interessados no crescimento e desenvolvimento de adolescentes e em suas doenças. Atualmente, começam a surgir cursos de pós-graduação a fim de formarem profissionais capacitados no atendimento do adolescente de forma integral (Teixeira $\left.{ }^{19}, 2005\right)$.

É importante salientar aos profissionais que cuidam de adolescentes - Hebiatras - "Hebe" do grego significa puberdade - e aos responsáveis pelo adolescente, que a funçáo do profissional será de coadjuvante ativo no processo, levando-se em consideração que o direcionamento e o apoio nessa etapa são inestimáveis, pois a contribuição será a de formar uma geraçáo saudável no conceito mais amplo da palavra (Bussadori e Masuda², 2005).

A Odontologia, atenta a todas as mudanças ocorridas durante esta fase da vida do jovem, procura dar-lhe atenção especial. O odontohebiatra ocupa-se em cuidar da saúde bucal do adolescente dando ênfase à prevençáo e promoção da saúde (Albuquerque e Simóes ${ }^{1}, 2003$ ). E também direciona e insere o adolescente em um pro- grama educativo-preventivo e curativo, se necessário, enfocando o aspecto estético e cosmético tão valorizados nessa fase (Bussadori e Masuda², 2005).

Diante dos fatos expostos, o propósito deste trabalho é, por meio da revisão da literatura, correlacionar as possíveis alterações que ocorrem durante a adolescência com suas implicações na saúde bucal.

\section{REVISÃO DA LITERATURA}

Por se tratar de um grupo entre 10 e 20 anos de idade, a atenção à saúde do adolescente inclui um amplo espectro da Odontologia (Valente ${ }^{22}$ 1998).

Para a adequada abordagem psicológica do adolescente, é preciso que o profissional conheça as características dessa fase do desenvolvimento, além de gostar de atendê-los, caso contrário, será impossível estabelecer um bom nível de aproximação (Souza $\left.{ }^{17}, 1996\right)$. Devese considerar que, nesse indivíduo em conflito e em desenvolvimento, muitas alteraçoóes estão ocorrendo e é de suma importância acompanhá-las. (Bussadori e Masu$\left.\mathrm{da}^{2}, 2005\right)$.

Para que haja uma boa interação entre profissional e adolescente, os pais, sempre que possível, devem ser incluídos. Entretanto, o profissional tenha em em mente que a figura central da consulta é o adolescente. Os pais, apesar de importantes, são figuras coadjuvantes durante o atendimento (Guimarães ${ }^{6}$, 1991; Saito ${ }^{12}$, 1999).

Ao abordar o adolescente, o profissional deve portarse de forma simples e honesta, sem demonstrar autoritarismo ou excesso de profissionalismo. Para estabelecer um relacionamento confortável, tenha-se o cuidado de não subjugar e intimidar o paciente, uma vez que sua auto-estima está fragilizada (Severo et al. $\left.{ }^{14}, 2004\right)$. Autores como Kaplan e $\mathrm{Mammel}^{8}$ (1997), acreditam que conversar com o adolescente como se fosse um paciente pediátrico ou como um indivíduo adulto pode interferir na comunicação e fazê-lo perder a confiança no profissional.

No atendimento de adolescentes considerados difíceis, podem ser utilizados métodos psicológicos ou farmacológicos. O diálogo, o método do dizer, mostrar, fazer e a hipnose, são considerados métodos psicológicos adequados para o controle do comportamento do adolescente no consultório odontológico (Carvalho et al. ${ }^{4}$, 1991).

Souza $^{16}$ (1998) classificou didaticamente o período da adolescência em três etapas:

- Precoce: dos 10 aos 14 anos, na fase em que todos 
Saiani RAS, Queiroz AM, Raffaini MSGG, Bagatin-Rossi CR. Odontohebiatria: uma nova especialidade na odontologia. Revista de Odontologia da Universidade Cidade de São Paulo 2008 jan-abr; 20(1):60-5

os esforços estão direcionados à aceitação das modificações físicas, conquistas da independência e separação dos pais, libertando-se das raízes da infância;

- Média: dos 15 aos 17 anos, na qual a maioria das características da puberdade já foram manifestadas. A preocupação maior seria com o culto à estética, através da cultura física e do vestuário, que geralmente tende a ocorrer de forma estereotipada;

- Tardia: dos 17 aos 20 anos, quando emergem os valores e os comportamentos adultos e predomina ou cristaliza-se uma identidade estável, buscando-se viabilidade econômica e estabilidade social.

$\mathrm{Na}$ adolescência precoce 12 dentes primários dão lugar à erupçáo dos dentes permanentes e com o aparecimento do $2^{\circ}$ molar permanente, aos 12 anos, completase a dentiçáo permanente. Variaçóes de 1 ano ou mais podem não ter nenhuma significância clínica. Os $3^{\text {os }}$ molares ou "dentes do ciso" irrompem na adolescência tardia entre os 18 e 20 anos (Valente $\left.{ }^{22}, 1998\right)$. Os $3^{\text {os }}$ molares são os dentes que se encontram mais freqüentemente ausentes na dentição adulta. Seu desenvolvimento inicia por volta de 4 ou 5 anos de idade e aos 10 anos a calcificação dos $3^{\text {os }}$ molares já é bem pronunciada tanto na maxila quanto na mandíbula. Se náo houver evidências de seu desenvolvimento até essa idade, existe a possibilidade de agenesia em torno de $50 \%$. Já a formação da raiz completa-se na idade de 14 a 16 anos. Se houver necessidade de extração desses dentes, por motivos ortodônticos, a cirurgia poderá ser realizada nesta época, pois haverá um significante decréscimo de complicaçóes pós-operatórias. Uma radiografia panorâmica dará uma posição exata sobre o assunto $\left(\right.$ Soxman $\left.^{18}, 2003\right)$.

O controle periódico e os programas preventivos têm muita importância nesse período, pela presença na cavidade bucal de dentes recém-irrompidos (Valente ${ }^{22}$, 1998).

A adolescência é um período de rápido desenvolvimento em todos os aspectos: físico, emocional, psicológico, social e espiritual. Fora o período pré e neonatal, é, de fato, a fase de mais rápido desenvolvimento humano (Albuquerque e Simóes ${ }^{1}$, 2003). O aumento na velocidade de crescimento, a mudança na composição corporal, a atividade física e a menarca (nas meninas), são fatores que caracterizam o início da puberdade e influenciam diretamente nas necessidades nutricionais, durante a adolescência (Bussadori e Masuda², 2005).

$\mathrm{O}$ envolvimento nutricional nessa fase assume aspectos singulares e muito importantes, pois é um período de rápido crescimento e transformações corporais intensas, quando o indivíduo ganha $25 \%$ de altura e $50 \%$ de peso total final e dessa forma deve existir uma alimentação equilibrada (Lopez-Joumet et al. ${ }^{9}$, 2005). O adolescente preocupado com sua aparência física, influenciado pelo relacionamento grupal característico do período, desconhecedor do valor nutritivo dos alimentos e freqüentemente com conceitos inadequados, está sujeito a hábitos alimentares impróprios, que podem vir a comprometer seu adequado crescimento (Lopez-Joumet et al. ${ }^{9}, 2005$ ).

Nos últimos anos, houve um grande aumento de refeiçóes irregulares, tendência a pular refeiçóes, alta ingestão de doces entre as refeiçóes e lanches, consumo inadequado de fast foods, dietas de emagrecimento muitas vezes sem acompanhamento médico, substituiçấo de sucos, leites e seus derivados por refrigerantes, café, chá e bebidas alcoólicas, o que poderia levar a desordens alimentares, obesidade, cárie dental, problemas periodontais e erosão dental (Majewski ${ }^{10}, 2001$; Soxman ${ }^{18}$, 2002; Bussadori e Masuda², 2005).

A substituição da atividade física pelo tempo gasto assistindo televisão e a influência da mídia levam ao consumo excessivo de bebidas açucaradas, refrigerantes e salgadinhos entre as refeiçóes, tornando o adolescente mais vulnerável a desenvolver lesóes de cárie (Bussadori e Masuda ${ }^{2}$, 2005).

Com relação às alterações periodontais, observamse controvérsias nos resultados de estudos que procuram estabelecer uma relação entre dieta e doença periodontal, na adolescência. Apesar das alteraçôes no biofilme dental, provocadas pela ingestão de sacarose, não existem evidências da associação entre o consumo de alimentos açucarados e a doença periodontal. Em geral o desenvolvimento da doença periodontal, no adolescente, é desencadeado pela mudança de comportamento, com negligência da higiene bucal, e alteraçóes hormonais (Bussadori e Masuda 2 , 2005).

Sendo assim a doença periodontal em adolescentes pode estar associada a uma higiene bucal pobre, pois a supervisão da higiene bucal em casa e o tratamento profissional tendem a diminuir de freqüência (Majewski ${ }^{10}$, 2001). Segundo alguns autores, a má higiene corporal e bucal do adolescente está relacionada com problemas de auto-estima e mudanças de comportamento devido às intensas transformaçôes que o adolescente vivencia nessa fase (Albuquerque e Simões ${ }^{1}$, 2003).

Denomina-se erosão dental o processo que ocorre quando uma superfície do esmalte é perdida sem en- 
Saiani RAS, Queiroz AM, Raffaini MSGG, Bagatin-Rossi CR. Odontohebiatria: uma nova especialidade na odontologia. Revista de Odontologia da Universidade Cidade de São Paulo 2008 jan-abr; 20(1):60-5

volvimento bacteriano. Esse processo de dissolução tem sido estudado e identificado em adolescentes (Soxman ${ }^{18}$, 2002), sendo induzido quimicamente como resultado do consumo de alimentos e bebidas com diminuição do $\mathrm{pH}$ - esse efeito pode ser causado pela concentração significativa de ácidos contidos em bebidas com ou sem açúcar. Existem evidências abundantes de que o consumo freqüente de sucos de frutas cítricas, particularmente de uva, limão e laranja, como também bebidas contendo estes sucos e algumas bebidas carbonatadas sejam capazes de ocasionar erosão dental (Sanders $\left.{ }^{13}, 2004\right)$. De acordo com Bussadori e Masuda ${ }^{2}$ (2005)o consumo exagerado de refrigerantes, disponíveis em máquinas muitas vezes instaladas em escolas ou o regurgitamento ácido característico da bulimia nervosa podem contribuir para a ocorrência de erosáo dental em adolescentes.

Hábitos alimentares alterados podem levar a sérios distúrbios como a anorexia nervosa, um distúrbio de ordem comportamental definido como inanição deliberada e auto-imposta, seguida de busca constante de magreza e medo mórbido de engordar e bulimia nervosa sendo também um distúrbio de comportamento caracterizado pela ingestão compulsiva de grande quantidade de alimentos, alternando-se com açóes dirigidas a evitar ganho de peso, como por exemplo, o vômito autoinduzido (Traebert e Moreira ${ }^{21}$, 2001). Nesses casos, as alteraçôes bucais são causadas principalmente pela alta ingestão de carboidratos e pela natureza ácida do vômito, que promovem a diminuiçấo do $\mathrm{pH}$ do meio bucal (Bussadori e Masuda², 2005).

Nos casos de desordens alimentares, além do aconselhamento dietético evitando bebidas e alimentos ácidos, devem-se prescrever cremes de baixa abrasividade e alta concentração de flúor, além de substâncias neutralizadoras da acidez como o bicarbonato de sódio. Um tratamento restaurador adequado utilizando o cimento de ionômero de vidro (CIV) por ser insolúvel em meio ácido é preconizado e o encaminhamento para uma equipe multidisciplinar deve ser feito (Traebert e Moreira ${ }^{21}$, 2001).

O profissional que lida com o paciente hebiatra deve incentivá-lo a adotar uma alimentação balanceada, tendo em vista que além da cárie dental, a obesidade também é uma das doenças nutricionais que mais tem aumentado nos últimos anos e está relacionada, em geral, com o sedentarismo, os hábitos alimentares inadequados e a velocidade das refeiçóes. Cerca de $80 \%$ dos adolescentes obesos tornam-se adultos obesos, e os fatores de risco, como hipertensão arterial, doenças coronarianas e alteraçóes do perfil lipídico, já ocorrem nesse grupo (Soxman $^{18}$, 2003; Sanders ${ }^{13}$, 2004; Bussadori e Masuda ${ }^{2}$, 2005).

Aliados às modificaçóes na dieta, medidas preventivas de auto-cuidado podem ser realizadas diariamente e devem ser sistematicamente recomendadas (Valente ${ }^{22}$, 1998). Torna-se então necessário reforçar aos adolescentes a importância da higienização correta para a manutenção da saúde bucal, orientando-os e ensinando-os, sempre adequando as conversas a essa faixa etária (Bussadori e Masuda ${ }^{2}$, 2005).

A escovação após cada refeição é o ideal, mas não se adapta à realidade, portanto é útil a recomendação de fazê-lo pelo menos antes de dormir. O fio dental também deve fazer parte da rotina diária de higiene bucal para remover o biofilme dos espaços interdentais (Valente ${ }^{22}$,1998). A utilização de flúor em todas as formas de administração local, pastas dentais e bochechos são comprovadamente importantes na prevenção da cárie dental (Soxman $\left.{ }^{19}, 2003\right)$.

Os aparelhos ortodônticos podem ser um fator agravante nos problemas gengivais, pois facilitam a retenção de restos alimentares e a adesão do biofilme; a vigilância e a correta higiene são imprescindíveis para impedir a patologia gengival nesses casos (Valente $\left.{ }^{22}, 1998\right)$. O controle da dieta e uma excelente higiene bucal devem ser realizados com o propósito de evitar, também, desmineralização ao redor dos braquetes. Vernizes fluoretados também são efetivos para esse objetivo. Assim, quando o aparelho for removido, o resultado será satisfatório (Sox$\left.\operatorname{man}^{19}, 2003\right)$.

As medidas citadas freqüentemente entram em conflito com o estilo de vida e as características próprias dos adolescentes, entretanto quando se promovem seminários de educação para a saúde realizados de forma multidisciplinar, como parte da rotina na programação escolar, essas informaçóes costumam ser valorizadas (Valente $\left.{ }^{22}, 1998\right)$.

$\mathrm{O}$ uso de drogas entre os adolescentes tem se tornado prática comum. Drogas são substâncias usadas para produzir alteraçôes, mudanças nas sensaçóes, no estado de consciência e no estado emocional. Geralmente o conceito diz que drogas são algumas poucas substâncias ou produtos ilegais como a maconha, cocaína e crack. Porém do ponto de vista da saúde, muitas substâncias legalizadas podem ser perigosas como, por exemplo, o álcool, que também é considerado droga (Albuquerque 
e Simóes ${ }^{1}$, 2003).

Para que o profissional esteja apto a lidar com pacientes hebiatras drogados é necessário que conheça os tipos de drogas mais comumente encontradas na rotina do consultório ou ambulatório, para também saber detectar, por meio de exame clínico e físico, as possíveis alteraçôes que possam estar ocorrendo na saúde geral e bucal (Bussadori e Masuda², 2005).

O uso de álcool, por exemplo, pode resultar em xerostomia transitória, aumento da glândula parótida, perda óssea vertical e horizontal, candidíase, acúmulo de placa (Albuquerque e Simóes ${ }^{1}, 2003$ ) e ainda segundo Meurman e Vesterinen ${ }^{11}(2000)$ leucoplasia e aumento do risco de câncer bucal. Já a cárie, doença periodontal e lesóes pré-cancerosas são observadas no uso do tabaco. O uso de drogas ilícitas como a cocaína resulta em cárie rampante com coloração escura, resistente e sem sensibilidade que é um sinal patognomônico além de outras manifestações como xerostomia, bruxismo, escaras na língua, lesóes na mucosa bucal e periodontite generalizada (Albuquerque e Simóes ${ }^{1}$, 2003).

Os usuários de drogas, ao perderem auto-estima, deixam de se preocupar com a higiene bucal, o que acarreta sérios prejuízos, como elevados índices de cárie, placa bacteriana e problemas na gengiva. $\mathrm{O}$ tratamento deve também ser preventivo, mas a presença de uma equipe multidisciplinar objetivando a remoção da droga é o mais indicado (Bussadori e Masuda ${ }^{2}$, 2005).

Prática comum entre os adolescentes é o uso do piercing na cavidade bucal, e desde 1992 já se tem relato de complicaçóes sistêmicas decorrentes do seu uso. Os locais mais freqüentemente usados são na língua, lábios e bochechas (Campbell et al. $\left.{ }^{3}, 2002\right)$. Dentre as complicaçóes na cavidade bucal podemos citar dor, edema, sangramento, infecções, lesôes de contato (Lopez-Joumet et al. $\left.{ }^{9}, 2005\right)$, recessão gengival, fratura dental, formação de cálculo e aumento de salivação (Theodossy ${ }^{20}$, 2003). Quando usado na língua pode levar a danos no nervo lingual, comprometimento da fala e deglutição (The- odossy $^{20}$, 2003) e em alguns casos língua bífida, como relatado por Fleming e Flood ${ }^{5}$ (2005). O tratamento indicado é a remoçáo do piercing, limpeza da área, bochecho com clorexidina e se necessário antibioticoterapia (Shacham et al. ${ }^{16}, 2003$ ).

A gravidez na adolescência também é algo que se deve relatar quando o assunto é saúde bucal de adolescentes, pois o número daquelas que passam por esta experiência é alto, e a gravidez durante essa fase pode ocasionar uma série de complicações. Para a realização do tratamento odontológico é necessário um termo de consentimento assinado pelos pais, e o profissional deve estar atento para a saúde geral da paciente, pois ela tem mais propensão a desenvolver hipertensão arterial e diabetes. $\mathrm{O}$ risco de parto prematuro e de nascimento de bebes de baixo peso é grande. As tomadas radiográficas devem ser feitas analisando-se o risco/benefício. Deve-se tomar cuidado ainda com a posição de atendimento, não colocando a paciente em posição supina, que pressiona o diafragma podendo causar dificuldade respiratória. Os achados bucais mais freqüentemente encontrados são: erosão dental, problemas periodontais como gengivite e hiperplasia gengival, tumores como o granuloma piogênico, mudanças salivares e cárie (Soxman ${ }^{18}$, 2003; Hilgers et al. $\left.{ }^{7}, 2003\right)$.

\section{CONCLUSÃO}

A dentição do paciente bem como sua saúde bucal e geral devem ser constantemente observadas durante a adolescência. Mudanças de comportamento que acompanham essa fase, bem como mudanças relacionadas ao processo fisiológico normal de desenvolvimento podem colocar esses indivíduos em situações de risco à saúde bucal. Assim a inclusão do adolescente em programas preventivos direcionados a eles, e uma abordagem cuidadosa, criteriosa e sensível por parte do profissional podem contribuir para que cheguem à vida adulta de maneira saudável. 


\section{REFERÊNCIAS}

1. Albuquerque ELD, Simões S. A saúde bucal do adolescente: ênfase no dependente de drogas e psicotrópicos. Escola de Aperfeiçoamento Profissional (Especialização em Odontologia em saúde coletiva). jul. 2003.

2. Bussadori SK, Masuda MS. Manual de odontohebiatria. São Paulo: Santos, 2005. 171p.

3. Campbell A, Morre A, Williams E, Stephens J. Tatakis, D.N. Tongue Piercing: Impact of time and barbell stem length on lingual gingival recession and tooth chipping. J Periodontol, 2002 Mar; 73(3):289-97.

4. Carvalho PC, Massara ML, Carvalho MBS. O adolescente e a odontologia. In: Maakaroun MF, Souza RP, Cruz AR. Tratado de adolescência: um estudo multidisciplinar. Rio de Janeiro: Cultura Médica; 1991. p.885917.

5. Fleming OS, Flood TR. Bifid tongue- a complication of tongue piercing. Br Dent J, 2005 Mar 198(5): 265-6.

6. Guimarães BEM. Relação médico-paciente e a conduta clínica na adolescência. In: Maakaroun MF, Souza RP, Cruz AR. Tratado de adolescência: um estudo multidisciplinar. Rio de Janeiro: Cultura Médica; 1991. p. 50-60.

7. Hilgers KK, Douglass J, Mathieu GP. Adolescent Pregnancy: a review of dental treatment guidelines. Pediatr Dent, 2003 Sep-Oct; 25(5): 459-67.

8. Kaplan DW, Mammel KA. Adolescência. In: Hay W.W. et al. Diagnóstico e tratamento em pediatria. $12^{\mathrm{a}}$ ed. Rio de Janeiro: Guanabara Koogan; 1997. p.40-52.

9. Lopez-Journet P, Camacho-Alonso F, Pons-Fuster JM. A complication of lingual piercing: A case report. Oral Surg Oral Med Oral Pathol Oral Radiol Endod, 2005 Feb; 99(2): 18-9.

10. Majewisk RF. Dental caries in adolescents associated with caffeinated carbonated beverages. Pediatric Dentistry, 2001; 23(3): 198-203.

11. Meurman JH, Vesterinen M. Wine, alcohol, and oral health, with special emphasis on dental erosion. Quintessence Int, 2000 Nov-Dec 31(10): 729-33.
12. Saito MI. Relação médico-adolescente. In: Marcondes E. Pediatria básica. $8^{a}$ ed. São Paulo: Savier; 1999. p.112-6.

13. Sanders TAB. Diet and general health: dietary counselling. Caries Res, 2004 38(1): 3-8.

14. Severo IF, Colares V, Rosenblatt. Abordagem psicológica da adolescente pelos cirurgiões-dentistas da cidade do Recife. Rev Ibero-am Odontopediatr Odontol Bebê 2004; 7(38): 377-86.

15. Shacham R, Zaguri A, Librus HL, Bar T, Eliav E, Nahlieli O. Tongue piercing and its adverse effects. Oral surg Oral Méd Oral Pathol Oral Radiol Endod, 2003 Mar 95(3): 274-276.

16. Souza RP. Abordagem do adolescente. In: Costa C.O.M., Souza R.P. Avaliação e cuidados primários da criança e do adolescente. Porto Alegre: Artmed; 1998. p.89-100.

17. Souza RP. Nossos adolescentes. $3^{\mathrm{a}}$ ed. Porto Alegre: Universidade Federal do Rio Grande do Sul; 1996.

18. Soxman JA. Considerations for treating adolescent patients. Gen Dent 2003 Jan-Feb, 51(1): 27-8.

19. Teixeira RS. Juventude: Uma época especial de ser. 2005. Disponível em http://boasaude.com.br/lib/ showdoc.cfm? $=3137$ fromcomm $=38 \mathrm{commrr}=\mathrm{src}>$ Acesso em: 10/02/2006.

20. Theodossy T. A complication of tongue piercing. A case report and rewiew of the literature. Brit Den J, 2003 May 194(10):551-2.

21. Traebert J, Moreira EAM. Transtornos alimentares de ordem comportamental e seus efeitos sobre a saúde bucal na adolescência. Pesqui Odontol Brás, 2001; 15(4): 359-63.

22. Valente MSG. Adolescencia y salud bucal. Adolesc Latinoam, 1998 out-dez; 1(3): 170-4.

23. World Health Organization. Physical status: the use and interpretation of anthropometry: report of a WHO expert committe. Geneva: WHO, 1995 p. 452.

Recebido em: 19/01/2007 Aceito em: 01/11/2007 